\title{
The GTNP Breeding Bird Monitoring Project: COVARIATION AMONG SITES IN BREEDING DENSITIES
}

\author{
M. L. CODY $\downarrow$ DEPARTMENT OF BIOLOGY \\ UNIVERSITY OF CALIFORNIA $\uparrow$ LOS ANGELES
}

\section{$\downarrow \quad$ INTRODUCTION}

The breeding densities of migrant birds are subject to a wide range of influences that may cause their variation, within a site from one year to another, within years but among habitats and sites from one location to another, and also among species with different migration strategies in terms of travel distances and wintering habitats. First measuring, and then understanding, this variation and its drivers is a substantial challenge for breeding bird monitors and population ecologists. Variation in breeding bird densities in Grand Teton National Park have been monitored since the early 1990 's, following protocols instigated by M. Cody \& S. Cain (1995 NPS Report). Of the thirty monitoring sites established by this report, one half to two-thirds have been censused yearly up to the present time, and a subset of the sites has been monitored yearly without discontinuities. Thus for many sites there is a census history of a decade or more, forming a data base that now approaches statistical adequacy for testing hypotheses about patterns of variation in breeding bird densities.

This report presents preliminary data on the covariation of breeding densities, within and between species, over the various monitoring sites. Given that many of the breeding birds leave GTNP in the nonbreeding season and overwinter elsewhere, early summer GTNP breeding densities are likely a consequence both of off-site conditions (winter survival and migration success) and on-site resources in the breeding habitat, likely in part weather-related. We ask questions such as: a) are there years when breeding densities are substantially higher than in other years? Are high-density years typical of many migrant species simultaneously, or do they occur independently over time among species? For a given species in a high-density year, are all breeding/monitoring sites occupied at higher density, with positive correlations among sites, or are some sites negatively correlated? Is the range of sites occupied by breeding birds greater in years when densities reach higher values in the most favored sites?

\section{$\downarrow \quad$ METHODS AND CONCEPTS}

Breeding bird densities were assessed at 15 monitoring sites in 2003, spanning a habitat range from grassland to forest. Sites are referenced numerically as in Fig. 1; a multi-dimensional scaling of the sites based on profiles of vegetation density (Fig. 2) produces a nearly one-dimensional array of sites corresponding to the ranking of Fig. 1.

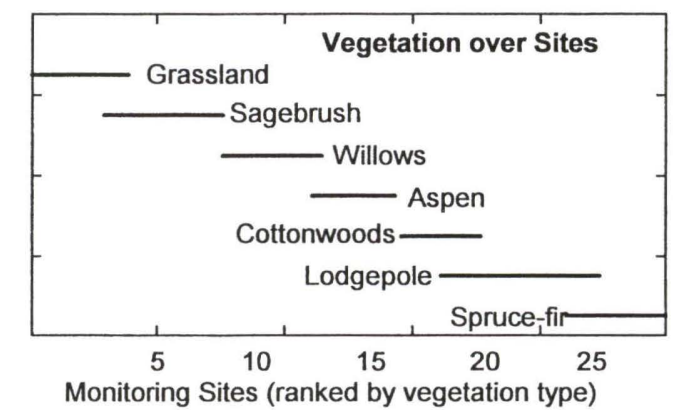

Figure 1. Range of vegetation types covered by breeding bird monitoring sites $1-25$, increasing in vegetation heightand density from left to right. 


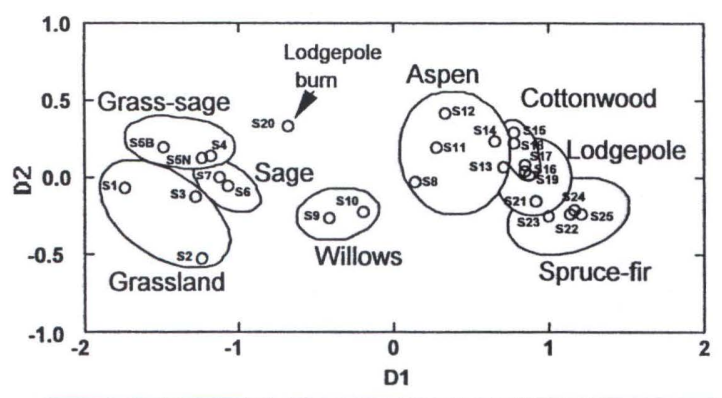

Figure 2. Multidimensional scaling (MDS) of monitoring sites by vegetation height, density, and distribution of density over height. The sites rank largely in one dimension D1, correlating to increasing vegetation height.

Most of the monitoring sites provide $\geq 10$ years of census data and, as most species occupy several of the monitoring sites, density variations over time at one site can be compared to density variations at another site, over the same time interval. In Fig. 3 are two alternative scenarios for variation in on-site resource density and parallel variation in bird breeding density. It is clear that, under Model 1, sites will be positively correlated in breeding density over years as resources vary. Under Model 2 negative correlations are possible, such that some sites will record high density when others are at low density, and low density when these others are high. Note further that the quality of breeding habitats is a function not only of independent effects such as weather variations, but also of the species' individual ecologies. Thus a grass-sage habitat perceived by species A to be of exceptionally high quality one year may be only average or of poor quality for another species B with which it is shared.
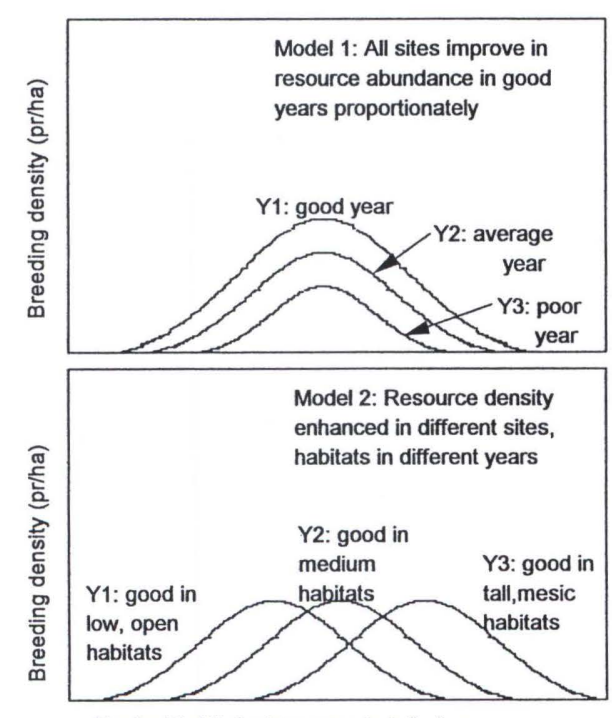

Ranked habitats: low, open to tall, dense

Figure 3. Alternative scenarios for variation in on-site resource abundance for breeding birds among years and across a vegetation gradient.

\section{$\uparrow \quad$ SOME Preliminary ReSUlts}

Some species have specific habitat requirements and thus occupy a narrow range of GTNP sites during the breeding season. Vesper Sparrow (Pooecetes gramineus) is an example, breeding in sites 4-7, dry grassy sagebrush. Variation in breeding density among years is lowest at sites where the species maintains the highest average density, and is high in the more marginal sites (Fig. 4. here and below, only sites with $\geq 10$ years of census data are used in the computations). In this species, the extent to which density variations among years are synchronized between sites, measured by simple correlation coefficients, are strongly related to the differences in habitat structure between the sites, measured as the Euclidean distance between vegetation heights and vegetation profile areas, log scaled. That is, sites similar in habitat structure are positively correlated in Vesper Sparrow densities over years, reaching similarly high or low densities in the same years. On the other hand, dissimilar sites tend to be negatively correlated in density, each reaching their respective high and low densities in different years (see Fig. 5). These data appear to support Model 2 of Fig. 3, in which certain sites are more productive in certain years, and others more productive in different years, rather than years that are better or poorer across habitats GTNP-wide.

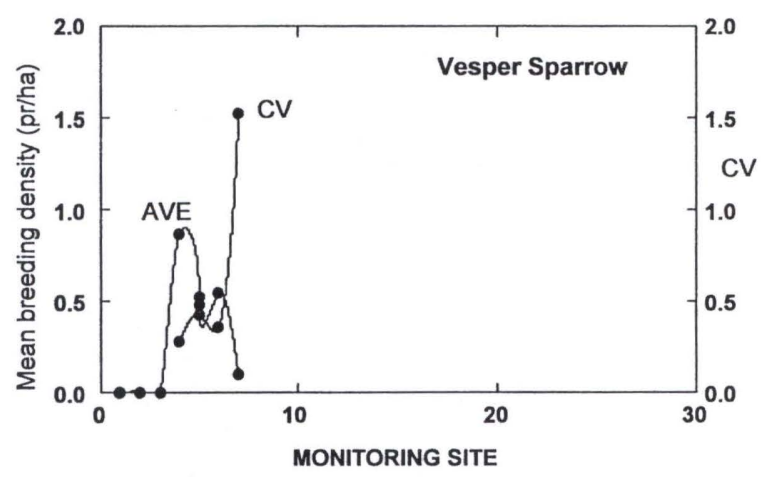

Figure 4. Mean breeding density (AVE) and its variation (CV) over years in a habitat specialist, Vesper Sparrow, in its narrow range of occupied habitats (abscissa).

Several emberizids are much more cosmopolitan in breeding habitat preference than the Vesper Sparrow. White-crowned Sparrow (Zonotrichia leucophrys) breeds in GTNP monitoring sites from brushy fields to willow, aspen and cottonwood habitats to coniferous forest clearings. In Fig. 6 mean breeding densities are given for this species over monitoring sites, and the variation (CV) of these mean densities, over years, is also shown. 


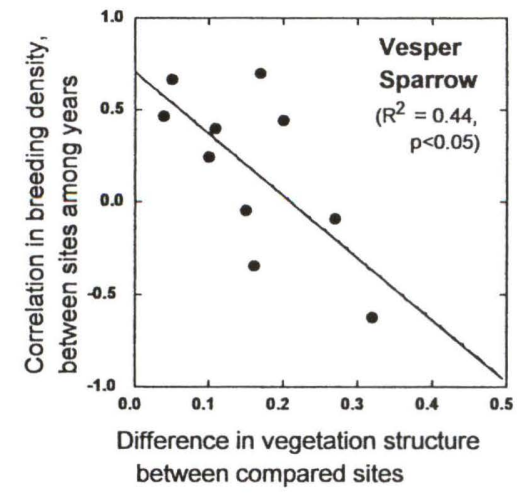

Figure 5. Breeding density variations in Vesper Sparrow, between paired sites among years, are similar (positive correlation) in structurally similar sites, but negatively correlated in structurally dissimilar sites.

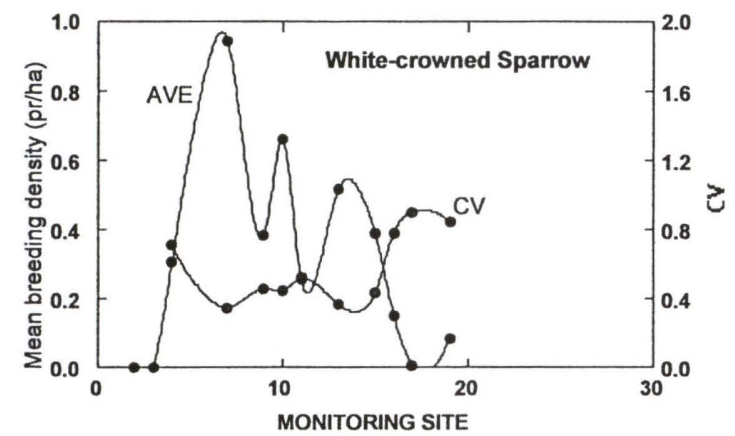

Figure 6. Mean breeding density (left-hand ordinate) over monitoring sites of White-crowned sparrow, and its variation among years ( $\mathrm{CV}$ : right-hand ordinate). Breeding densities are least variable in high-density (preferred) habitat, most variable in marginal habitats.

In this widely-distributed species, there is no clear pattern to the covariance of densities between sites, and structurally similar sites are no more or less likely to covary in density in similar ways. Some closely-adjacent sites, such as 4: JLJ Grass-sage and 11: Oxbow Willow-aspen, vary in White-crowned Sparrow density in significantly similar ways $(r=$ $0.776, \mathrm{p}<0.05$ ), but others nearby (e.g. 10: JLJ Wet Willows) show unrelated density variations $(\mathrm{r}=-0.096$, -0.109 respectively, NS). Density variations over years at Site 4 are significantly negative correlated with those in Site 15: Spread Ck Cottonwoods $(r=$ $-0.754, \mathrm{p}<0.05$ ), but even those sites that regularly support the higher densities (Sites 7, 9, 10, 15) do so in generally different years from each other.

A second widely distributed species, of woodland rather than scrub sites, is Chipping Sparrow (Spizella passerina). Fig. 7 shows its distribution over sites, with the higher densities recorded in lodgepole pine woodland.(e.g. Site 18: Timbered Island pines). As before, CV's of breeding densities are generally low at sites with overall high breeding densities, high at marginal sites. Density variations among years are all positively correlated among the four coniferous forest sites $(18,19,21$, $25)$, significantly so between sites $18-21(\mathrm{r}=0.763$, $\mathrm{p}<0.05$ ), indicating a potential for these habitats to vary in Chipping Sparrow resources in similar ways year to year. As a group, these coniferous forest sites show Chipping Sparrow densities that are negatively correlated with the species' density in aspens and cottonwoods (Sites 12, 14, 15, 16). These patterns again support the hypothesis that certain sorts of habitats are more productive in certain years, and different habitats are more productive in other years. With more data, an increased resolution of these patterns should be possible.

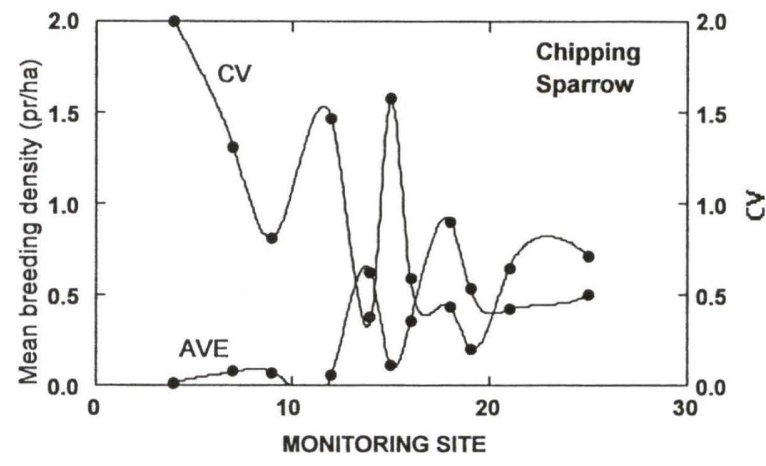

Figure 7. Variation (CV: right-hand ordinate) in breeding density of Chipping Sparrow (left hand ordinate) over monitoring sites among years. 